\title{
Developing agency in a writing centre context: A Social Realist interpretation
}

\author{
Fatima Slemming \\ Social Work Department (Child and Family Studies Programme), University of the Western Cape, South Africa \\ E-mail: slemmingf@gmail.com
}

\begin{abstract}
The aim of this article is to explore how aspects of a Social Realist theoretical framework could be understood in relation to my professional development as a writing centre consultant and manager. I share the view that a Social Realist framework could enable consideration about processes of developing or extending knowledge about ourselves in relation to cultural and structural phenomena in society, and may explain how or why changes occur or remain unchanged in socio-cultural settings. The research question that this article sets out to address is: How can my internal reflexive conversations help explain my professional development? I begin the theoretical framing for this paper by means of a brief introduction to Critical Realism (Bhaskar 1998, 2008, 2009). This is followed by a discussion of Social Realism (Archer 1995, 1996, 2000, 2007, 2010). I present introductory explanations of the major concepts used in the Social Realist theoretical framework, namely 'structure', 'culture and 'agency', and I explain related concepts necessary for analytical sense-making. The article focuses on the concept of 'agency' (Archer 2007, 2010), at which point the concepts of 'reflexivity' and 'internal conversations' are discussed. The research approach used is qualitative research, utilising an autoethnographic methodology developed from ethnographic records of my professional life over a period of 25 years. I use mini-narratives based on self-interviews as the research method. Part theoretical explanation, part reflexive account, this article attempts to convey a narrative about how I have used Social Realism to make sense of aspects of my development as a writing centre practitioner-researcher in South African higher education.
\end{abstract}

Keywords: Social Realism, writing centres, autoethnography, reflexivity, agency

\section{Introduction}

The aim of this article is to explore how aspects of a Social Realist theoretical framework (Archer 1995, 1996, 2000, 2007, 2010) could be understood in relation to my use of theory, research methodology, and my pedagogical practices as a writing centre consultant ${ }^{1}$ and

1 I started working as a 'writing consultant' in 1994. I have worked in writing centres at the University of the Western Cape, the University of Cape Town, and the Cape Technikon before the latter became the Cape Town campus of the Cape Peninsula University of Technology. 
manager ${ }^{2}$. I share the view that a Social Realist framework could enable consideration about processes of developing or extending knowledge about society, culture, and human agency, and may be able to explain how or why changes occur or remain unchanged in socio-cultural settings. The research question that this article sets out to address relates to influences that have been instrumental in shaping my pedagogical practices and professional development as a writing centre practitioner-researcher. The question I am posing is: How can my internal reflexive conversations help explain my professional development?

Part theoretical explanation, part reflexive account, this article attempts to convey a narrative about how I have used Social Realism to make sense of my development as a writing centre practitioner-researcher in South African higher education over a period of 25 years. The parts of the story that will unfold are not intended to be read as a chronological account of experience, but rather as memorable experiences or significant moments that can be interpreted as having contributed to how writing centres may have undergone morphogenesis over time, and also how I consider my understanding of what it means to be a practitioner-researcher in this professional context to have developed.

In terms of an exposition of the basic tenets of Social Realism, there are a few concepts that need explanation. These include the notions of 'culture', 'structure', and 'agency'. However, Archer $(1995,1996)$ contends that, while each of these concepts can be analytically separable, it is the interplay between agency and culture, and/or agency and structure that can activate meaningful analysis of social configuration within a cultural domain. In the first part of this paper, these concepts will be discussed. Related concepts necessary for analysis are 'analytical dualism', 'conflationary thinking', 'emergence', 'social and system integration', and the ideas of 'morphogenesis' and 'morphostasis'.

Following the introduction of the above concepts, the article will focus on the role of agency in order to link the basic concepts and ideas of Social Realism to writing centre theory and practice, and, in particular, my professional learning as a writing centre practitioner-researcher. The concepts of 'reflexivity' and 'internal conversations' will be discussed at this point. For the purpose of providing a reflexive analysis of my professional development, I suggest that the concept of 'reflexive deliberation' or 'internal conversation' could be applied usefully in an exploration of how 'agency' can develop over time. I will also discuss how certain instances of interplay between the "parts" and the "people" (Archer: 1995) of the Social Realist theoretical framework may have influenced my professional development over time.

\section{Critical Realism}

I begin the theoretical framing for this article by means of a brief discussion about the origins of Critical Realism. Critical Realism is a philosophical theory advanced by Roy Bhaskar since the 1970s (1998, 2008), out of which Margaret Archer (1995, 1996, 2000, 2007, 2010) developed Social Realism, the social theory that I use throughout the paper to make sense of key aspects of my working experience and development as a practitioner-researcher in writing centres. To understand the basic concepts and argument of Social Realist theory, it is useful to briefly describe what Critical Realism is about.

2 I was the coordinator of the University of the Western Cape Writing Centre from 2003 until 2008. 
While Social Realism engages with aspects of knowledge about self, social structures, and cultural systems, the theory of Critical Realism offers a perspective on making sense of knowledge about reality. Critical Realist thought posits that there is a reality that is possible to be known although it may not be apparent due to the fact that reality is "differentiated, structured and stratified", and consists of "a set of internally related objects" or relations of which some are necessary while others are contingent (Danermark, Ekström, Jakobsen and Karlsson 2002: 47). Reality is also stratified according to a natural world or a social world. The natural world consists of the physical world, while social world strata include social structures, cultural systems, and agents (Archer 1995). It is only when there is an understanding that reality exists on different levels and in different domains that this type of knowledge about reality can be developed. The domain of the social world is the one that this paper sets out to explore in more detail.

Bhaskar (2008: 46-47) distinguishes between three levels of reality, which he refers to as the domains of "the Empirical", "the Actual", and "the Real". The Empirical is a reference to the observable world in which we live; in other words, that which we perceive, observe, experience, and can sense and understand. The Actual relates to events that can be experienced. These events occur whether we participate or know of them or not. The level of the Real has causal powers from which events in the Actual domain emerge or from which generative mechanisms are activated. We do not really have any control over the domain of the Real as it exists independently of human influence and knowledge in both the natural and the social worlds.

The basic premise of a Critical Realist ontology is that the world is an open system. In their description of what an open system is, Danermark et al. (2002: 206) state that, "[when] generative mechanisms operate in combination with each other, the more mechanisms involved, the more difficult [it is] to anticipate the outcome". Clear connections between what causes certain experiences (effects) to come about in society cannot be made easily as people interpret experiences differently, and also implement things differently depending on their variable contexts (Archer 1996, Sayer 2000). However, knowledge of the world is fallible or corrigible (Archer 1995, Sayer 2000), thus we can never claim to know the world fully because it is an open system.

Bhaskar (2008: 234) argues that there are two dimensions of knowledge that should be considered. On the one hand, knowledge is transitive (changing) and, on the other, intransitive (enduring and unchanging). Transitive objects of knowledge come about as a result of what people produce in their social activities, which can emerge from the level of the Real. Transitiveknowledge objects exist on the level of the Actual (changing due to historical and social contexts), and the level of the Empirical (experienced or observed by our senses). Bhaskar (1998) considers transitive-knowledge objects as fallible social products. Intransitive-knowledge objects, on the other hand, exist in the domain of the Real. These are any material, spiritual or natural objects that exist in the natural and social worlds over which people have no control or even, perhaps, knowledge. Because knowledge of the world and causal mechanisms for what happens or is apparent in the world are dependent on what concepts are available to explain levels of reality, it is always possible to dig deeper and uncover more fundamental causal mechanisms.

To help make sense of the three levels of reality that Critical Realism explains, I introduce one other concept that has relevance for research in which a basic understanding of the theory of Critical Realism is necessary. When I began to ponder over how I would set out to answer the research question I have posed in this article, I decided that a logical place to start would be to search for 
literature of research studies that have been conducted about South African writing centres in which the theories of Critical Realism and Social Realism have been used. I did not find any.

I also needed a research methodology that could assist me to work with the type of research data about my professional experience and learning that I wanted to highlight as the object of research. I started reading about autoethnography, and found it quite suitable in that it provided a research perspective through a concept known as 'reflexivity' which is shared with Critical Realist theory and the Social Realist theoretical framework. However, I did not find any published literature about autoethnographic research conducted in writing centre contexts in South Africa.

With no previous research using the theoretical frameworks and research methodology that I needed to engage with in order to write this article, I turned my attention to considering the type of reasoning that I needed to use in order to start making sense of data about my professional development. I discovered that I was not going to be able to use either inductive, deductive or abductive reasoning ${ }^{3}$. Miller and Brewer (2003:1-2) state the following:

Processes of logical inference in real research are in fact quite messy. Ideas for research will come partially from the researcher's conceptual knowledge, partially from their personal experiences and perhaps partially from intuition [...] Research is not pure with distinct stages of deduction, induction or abduction, but a combination of all three, often going on simultaneously. Retroduction is a term applied to this process that recognizes its 'retro' or constant backtracking nature.

According to Willmott (2002: 8), Critical Realism, also described as "transcendental realism", enables a researcher to ask the question, "How must things be for X to be possible?". I realised that I needed to use retroductive reasoning in order to move back and forth between data sets in order to bring the aspect of reflexivity to the fore in relation to understanding my professional development. Critical Realism can be considered a metatheory because it is primarily concerned with conceptualising and providing explanatory power to abstract thoughts of what constitutes knowledge about levels of reality. In order to keep the link between Critical Realist philosophy and Social Realist conceptual framing on a logical continuum during the data analysis process, I found retroductive reasoning useful for enabling me to identify some of the constraints for this study of my professional development in a South African writing centre context.

It became possible for me to identify that there is no readily available literature of an Empirical level of reality in which writing centres function, as seen from research informed by a Critical Realist perspective. I could also identify that the work that is being conducted in writing centres in the South African higher education context has not been analysed using Critical Realist or Social Realist theoretical framing. In other words, on the level of the Real (with its causal powers, and from which generative mechanisms are activated), there was no research-based evidence of where or how certain situations that were occurring in writing centres were giving rise to changes as a result of events or contextual influences and experiences. I came to the realisation that, in order for me to do the reflexive writing that I set out to do in this article, I needed to learn to

\footnotetext{
${ }^{3}$ Deduction, induction, and abduction are types of logical reasoning that are most often associated with positivistic (rational, scientific) research. See Miller and Brewer (2003: 1-2) for more.
} 
identify causal tendencies and generative mechanisms that could help explain where and how the level of the Actual was emerging from the level of the Real in the context of a writing centre.

Bearing in mind this understanding of the differentiated nature of reality and knowledge objects in an open system, as well as the type of logical reasoning I needed to employ in order to realise the aim of this article, I introduce in the next section the basic concepts of the Social Realist theoretical framework.

\section{Social Realism and its explanatory powers}

In terms of an exposition of the basic tenets of Social Realism, there are a few concepts that require explanation. These include the concepts of 'culture', 'structure', and 'agency'. As mentioned earlier, Archer $(1995,1996,2000)$ contends that while each of these concepts can be analytically separable, it is the interplay between agency and culture and/or agency and structure that can activate meaningful analysis of social configuration within a cultural domain. In the first part of this section of the paper, these concepts are discussed. Related concepts which are necessary for analysis include 'analytical dualism', different concepts relating to 'conflationary thinking', the concepts of 'emergence', 'social and system integration', and the ideas of 'morphogenesis' and 'morphostasis'.

\subsection{Culture, structure, and agency}

In a society characterised by a transformative trajectory, Margaret Archer's theory of Social Realism $(1995,1996)$ provides a theoretical framework "for explicating processes of social change or reproduction" (Vorster 2010: 18). Archer's Social Realist framework offers a more practical perspective on how to differentiate between what occurs in society that can influence social change (morphogenesis) or, through identification or reproduction, can maintain the status quo (morphostasis).

Archer (1995) argues that any society or social world is made up of "parts" and "people". The "parts" refer to the prevailing social structures or cultural system that exists. The term "culture" refers to "the ideas, beliefs, theories, values, ideologies and concepts which are manifest through discourses used by particular people at particular times" (Quinn 2012: 29). In a higher education system, for example, institutional discourses of "transformation (including access, equity and redress), quality assurance and teaching and learning" are identified as being present in varying degrees in all higher education institutions (Quinn 2012: 29). On the other hand, "structure" refers to (physical and human) material interests (Archer 1996). Quinn (2012: 36) states that "[material] relations are often legitimated and maintained by ideas from the cultural system [and in] some cases, changes in the structures can contribute to changes in the culture of an institution". According to Archer (1995), the "parts" precede the actions of the "people" because structures and cultures always pre-exist the situations into which people enter. The "people", also referred to as "agents", are those who operate within a particular structural or cultural system. In the interplay between structure, culture, and agency, emergent properties come about, and emergent powers are exercised as agents interact with structure or culture.

Archer argues that structure and culture parallel one another, and that there is a link between them. In other words, there are internal and necessary relationships between emergent properties (Archer 1995: 168). Using the same conceptual, theoretical, and analytical framework for 
investigating structure and culture allows for a comparison of the effects of each on social life, and to explore the interplay between each of them with agency. People and structures in society are also not different aspects of the same thing but, rather, radically different in kind, according to Motshoane and McKenna (2014). Structure and culture are both central to social life yet they are relatively autonomous from each other. It is in the interactions between structure and agency or culture and agency that social reproduction or change can be discerned.

\subsection{Emergent properties}

There are three types of emergent properties which can be identified namely, structural emergent properties (SEPs), cultural emergent properties (CEPs), and personal emergent properties (PEPs) (Archer 1995, 1996). The first two are a reference to the "parts" that make up the social world, and the latter refers to "people". It is understood that the emergence of SEPs depends primarily on material interests and resources, including people. CEPs can come about as changes in ideas, beliefs, values, rules, and so on, which then become part of the cultural landscape in a morphogenetic cycle (Archer 1995: 176-180, Archer 1996: 107). It is also possible that PEPs can emerge as people interact in different contexts where they are required to exercise different sets of powers, either as part of new groups or where their interactions are challenged within the natural, practical or social realms of reality.

\subsection{The morphogenetic approach}

Social Realism is a social theory that has been found useful for research into higher education because it is possible to relate the analytical framework to higher education contexts as sociocultural environments. However, Archer (1995: 57-58) argues that:

no social theory can be advanced without making some assumptions about what kind of reality it is dealing with and how to explain it. All social theory is ontologically shaped and methodologically moulded even if these processes remain covert and scarcely acknowledged by the practitioner.

The term "morphogenesis" was coined by Walter Buckley (1967: 58), and is defined as "those processes which tend to elaborate or change a system's given form, structure or state". Archer takes a morphogenetic approach which essentially advocates that social change is possible when the constant interplay between structure and agents, or culture and agents, leads to an understanding of the relative influence of structure or culture on agency or vice versa. The interplay usually occurs as part of a morphogenetic cycle which is understood to span a certain period of time. In morphogenetic cycles, because society is constantly evolving, it is possible that structural, cultural, and agential emergent properties and powers can come into being, and can bring about change through the influence of ideas held by agents. The morphogenetic approach is "a tool for examining the dynamics by which the 'parts' and the 'people' shape and re-shape one another through their reciprocal interaction over time" (Archer 1995: 194). Thus, it is conceivable that, as a researcher explores aspects of the interplay between structure and agency or between culture and agency based on assumptions about a perceived reality, it can become possible to identify and explain changes in the cultural or structural system over a period of time. "Morphostasis", in contrast, refers to processes in complex systems which tend to ensure that the system remains unchanged over time (Archer 1995: $75 \mathrm{fn} \mathrm{11).} \mathrm{It} \mathrm{is} \mathrm{my} \mathrm{understanding} \mathrm{that}$ morphostasis should not be viewed as a negative process and, as I shall point out later, it may 
also be possible to identify morphostatic elements within a morphogenetic cycle and vice versa. Social Realism could thus be considered to be about the processes of developing or extending knowledge about society, culture, and agency, and to be able to explain how or why changes occur or remain unchanged in a system.

\subsection{Analytical dualism and the fallacy of conflation}

'Analytical dualism' is the concept advanced in Social Realist theory that rejects all forms of conflation of the "parts" (structure and/or culture) and the "people" (agents) (Archer 2000: 6). Archer cautions against the "fallacy of conflation" which can occur as upwards, downwards or central conflation (Archer 1996, Carter and New 2004, Sibeon 2004).

Upwards conflation occurs when the powers of the "people" are considered to be superior to those of the "parts". In other words, in upwards conflation, the role of people - most likely those with a great deal of access to available resources - could mistakenly be assumed to indicate that they can effect significant social transformation despite prevailing cultural conditions. Downwards conflation, on the other hand, is a reference to thinking that the "parts" exert more power and influence over the actions of the "people", and that personal or corporate agency is primarily determined by affordances within the structural and/or cultural domain. In central conflation, autonomy and authority are withheld from both the "parts" and the "people" because they are mutually constitutive, and are not considered in their own right (Motshoane and McKenna 2014). In other words, neither the parts nor the people can exert much influence over one another. Morphostasis, preservation of the status quo, and stability are assumed in this type of conflationary thinking.

However, according to Danermark et al. (2002, in Motshoane and McKenna 2014: 4), "'dualism' refers to the fact that social structures and human agency are different strata, 'analytical' to the fact that these strata and the interaction between them cannot be detected in the flow of social action and human experiences, but only by means of social scientific analysis". In an open social system, it is unlikely that any form of conflationary thinking can continue unabated due to the dynamic interplay of culture, structure, and agency in morphogenetic cycles that can only be discerned through analysis.

\subsection{Social integration and system integration}

Another important set of concepts consists of 'social integration' and 'system integration'. According to Archer (1996), to study structure/culture and agency, the "parts" and the "people" need to be separated theoretically. This is known as the process of distinguishing between "social integration" and "system integration" in order to explain structure and agency (Lockwood 1964, in Archer 1995: 67; Archer 1996). Social integration refers to the degree to which relations amongst groups of people are orderly or conflicting. System integration is about the extent to which relations between the "parts" of the social structure are orderly or conflicting. This is a point of distinction to which I shall return later in the paper in relation to its relevance for discerning morphostasis and morphogenesis. 


\section{Developing agency}

Following the introduction of the above concepts, the focus of the article shifts to the concept of 'agency', and Archer's (2000) explanations of personal agency, corporate agency, and what leads to becoming an Actor. This is done in order to link the basic concepts and ideas of Social Realism to writing centre practice and, in particular, my understanding of the development I have undergone as a writing centre practitioner-researcher. The concepts of 'reflexivity' and 'internal conversations' are also discussed at this point.

\subsection{Forms of agency}

Archer (2000) discusses the section of Social Realist theory that deals with "people" in terms of human agency. She distinguishes between different forms of agential powers and properties. Archer makes a distinction between "personal agency" and "corporate agency" to refer to the stages of agency that people go through as they interact with given structures and cultures. The former refers to the actions of individuals, and what they are capable of doing in their personal capacity within a collective.

Personal/primary agents are defined as "collectivities sharing the same life chances" (Archer 2000: 263). These are people who are born into existing social and cultural structures which constrain or enable how they can or cannot act, and they "play no part in the strategic guidance of society because they literally have no say" (Archer 2000: 268). In normative society, this could be a reference to any persons with a minority status, such as children, women, and black people. In a professional or academic environment, it could refer to any persons who, even as a collective, may not have or know about constructive avenues for offering their opinions and ideas, perhaps due to a prevailing bureaucratic culture or excessively rule-bound or status-bound cultural ethos.

Corporate agents are groups "who are aware of what they want, can articulate it to themselves and others, and have organized in order to get it, can engage in concerted action to re-shape or retain the structural or cultural feature in question" (Archer 1995: 258). The latter is a reference to what individuals are capable of doing as representatives of the interests and values of a given structure or culture. This is usually only possible after considerable immersion or experience with a structure or culture. Archer refers to such a person as someone who has developed "corporate agency".

An Actor is the last category of "people" on whom Archer elaborates. This is someone who has internalised the mission or purpose of the issue for which $\mathrm{s} / \mathrm{he}$ is a corporate agent to the extent that $\mathrm{s} /$ he can independently act upon matters that are considered important in relation to the structural emergent properties and/or cultural emergent properties s/he encounters. However, an Actor rarely succeeds in innovating or undergoing morphogenesis individually.

Furthermore, according to Archer (2000: 308),

[human] beings have the powers of critical reflection upon their social context and creatively redesigning their social environment, its institutional or ideational configurations, or both [...] it is possible for human beings to become agentially effective $[. .$.$] in evaluating their social context, creatively envisaging$ alternatives, and collaborating with others in bringing about transformation. 
This process, where primary agents develop into corporate agents and Actors, can usually only occur over a sustained period of time, and after considerable immersion in a particular cultural system. By virtue of their developing insights based on experience and enhanced knowledge and understanding, corporate agents strive towards effecting changes to the social order in the cultural system because of their vested interests and shared goals. The process, as I understand it, occurs as a result of reflexivity, which is also referred to as the "adult internal" or "inner conversation" (Archer 2000).

\subsection{Reflexivity / internal conversations}

Reflexivity is defined as "the regular exercise of the mental ability, shared by all normal people, to consider themselves in relation to their (social) contexts and vice versa" (Archer 2007: 4). According to Quinn (2012: 45), reflexivity is "used by individuals to balance the private and the social and the competing roles within each [and the] inner conversation is about referential reflexivity - thinking about reality, about the world, and what one's place in it is and should be". Moreover, Archer (2007: 5) asserts that people's reflexive "internal conversations [are] the means by which we make our way through the world".

For the purpose of providing a reflexive analysis of my professional development, I suggest that the term "reflexive deliberation" or "internal conversation" could be applied usefully in an exploration of how "agency" can develop over time. I now proceed to outline the research methodology I have used, namely autoethnography. I have selected autoethnography as the research methodology for this article because of its complementarity in terms of the research contexts in which this methodology has become used, and also because reflexivity is an essential characteristic of autoethnographic research.

\section{Research methodology}

In keeping with an interpretivist research tradition, the research for this article was conducted as qualitative research, utilising an autoethnographic methodology consisting of ethnographic records of professional practice, and narrative self-interviews documented over a period of 25 years.

This section sets out to present, and to represent, some of my memories, work-diary entries, and interpretations of professional experiences in the context of writing centres, a specific socio-cultural environment in the South African higher education system. Autoethnographic research, as a method that is autobiographical, ethnographic, and flexible enough as an analytical approach, was found to be a particularly useful means to provide a theoreticallyinformed, reflexive interpretation of documented practice, experiences, observations, and memory over a 25-year time span. Brodkey (1996: 29) elaborates:

Autoethnography invites writers to see themselves and everyone else as human subjects constructed in a tangle of cultural, social and historical situations and relations in contact zones ... [and while] autoethnography contains elements of autobiography, it goes beyond the writing of selves. Writing that crosses personal and professional life spaces goes further than autobiography whenever writers critique the depersonalizing tendencies that can come into play in social and cultural spaces that have asymmetrical relations of power. 
The term "autoethnography" was first introduced by Heider, an anthropologist (1975, in Chang 2008). Autoethnography is a social-scientific mode of enquiry that contains elements of autobiography and ethnography (Brodkey 1996, Ellis and Bochner 2000, Bochner and Ellis 2006, Chang 2008, Denshire 2013, Méndez 2013). Denshire (2013: 2) explains that "autoethnography is informed by a range of disciplines [and writers] of these accounts address social questions of difference and becoming that may enable voices previously silenced to speak back". Chang (2008: 51-52) claims that:

[autoethnography] is becoming a particularly useful and powerful tool for researchers and practitioners who deal with human relations in multicultural settings, such as educators, social workers, medical professionals, clergy, and counselors. The benefits of autoethnography lie in three areas: (1) it offers a research method friendly to researchers and readers; (2) it enhances cultural understanding of self and others; and (3) it has a potential to transform self and others to motivate them to work toward cross-cultural coalition building.

According to Méndez (2013:279), "the aim of autoethnography is to recreate the researcher's experience in a reflexive way, aiming at making a connection to the reader which can help him or her to think and reflect about his or her own experiences". Chang (2008: 51) states that "all aspects of life can become a subject of autoethnography [and the] minimum requirement is that autoethnographers must be willing to dig deeper into their memories, excavate rich details, bring them onto examination tables to sort, label, interconnect, and contextualize them in the sociocultural environment".

Bochner and Ellis (2006) and Anderson (2006: 387) identify the different approaches in autoethnography in terms of "evocative" and "analytical" approaches. The former foregrounds the writer's personal stories while the latter connects to "some broader set of social phenomena than those provided by the data themselves". The research conducted for this article made use of an analytical approach. Anderson (2006: 378) sets out the following defining characteristics for analytic autoethnography, which Chang (2008: 46) endorses:

(1) complete member researcher (CMR) status;

(2) analytic reflexivity;

(3) narrative visibility of the researcher's self;

(4) dialogue with informants beyond the self;

(5) commitment to theoretical analysis.

The research process followed in autoethnographic research, according to communication scholars such as Carolyn Ellis, Tony Adams, and Art Bochner, categorises an autoethnographic research method "as both process and product", reiterating that "a researcher uses tenets of autobiography and ethnography to do and write autoethnography" (Ellis, Adams and Bochner 2011: 273). Chang (2008: 48-49) adds the following to this explanation:

First, like ethnographers, autoethnographers follow a similar ethnographic research process by systematically collecting data, "field texts", in Clandinin and Connelly's (2000) words, analyzing and interpreting them, and producing scholarly reports, also called autoethnography. Second, like 
ethnographers, autoethnographers attempt to achieve cultural understanding through analysis and interpretation. In other words, autoethnography is not about focusing on self alone, but about searching for understanding of others (culture/society) through self.

Field data in autoethnographic research is typically collected by means of participation, observation, (self-)interviews, document reviews, and data verification by triangulating sources and contents from multiple origins. Thereafter, the data is analysed and interpreted to decipher the cultural meanings of events, behaviours, and thoughts, and the ethnography is written (Chang 2008: 49).

Moreover, Mizzi (2010) states that traditional forms of ethnography rarely take into account a researcher's connected life experiences. Mizzi (2010:2) argues that autoethnographic research is a form of critique about ethnographic methodology that "finds a place and presence for the researcher's life experience that would otherwise be overlooked through traditional ethnographic methods". The notion of 'reflexivity' is also central to this view about the value of autoethnographic research.

Chang (2008) also identifies some of the pitfalls to avoid when conducting autoethnographic research. These include:

(1) excessive focus on self in isolation of others; (2) overemphasis on narration rather than analysis and cultural interpretation; (3) exclusive reliance on personal memory and recalling as a data source; (4) negligence of ethical standards regarding others in self-narratives; and (5) inappropriate application of the label "autoethnography".

Chang (2008: 57)

With the above guidelines in mind for conducting autoethnographic research, I present three mininarratives in the next section of this article which serve as reflexive, autoethnographic accounts of situations or events that I consider to be significant moments of my professional learning in writing centre spaces. I also discuss how certain instances of interplay between the "parts" and the "people" of Social Realism, the complementary theoretical framework I am applying to make sense of the research data, may have influenced my professional development over time.

\section{My stories}

The following mini-narratives include contextual descriptions of the time-bound phases in which I have worked in and around writing centre-focused practice. They refer mostly to my engagement in a particular working context namely, the University of the Western Cape Writing Centre between 1994 and 2008, and also in the field of higher education studies up until now. My relationships with writing centre or writing-lab colleagues at other universities are also explored in reflections about network development and a sustainability agenda for South African writing centres.

There are three stories, arranged in the following order: (i) Story A - The Early Years, (ii) Story B - The Middle Period, and (iii) Story C - Recent Developments. Each story contains an interpretive section that provides a Social Realist interpretation of the story contents. 


\subsection{Story A - The Early Years}

This story relates to my early years as a writing consultant in various writing centres at higher education institutions in Cape Town, where most of the first writing centres were established. I was one of a small group of postgraduate students who formed part of the first team of writing consultants at the University of the Western Cape. This writing centre was established as a pilot project run by the Academic Development Centre (ADC) at the university. Faculty Academic Development Officers were responsible for our training and establishing relationships with course coordinators in faculties. Most writing consultants were students in these faculties as well. This writing centre was established in 1994 - the year in which South Africa became a democratic country - as a transformative pedagogical space in an environment where large-class lecturing and transmission modes of teaching were the norm. This centre was different in the sense that its focus was to work with student writers on a one-to-one, student-centred, consultative basis using a peer-teaching and -learning framework (Leibowitz and Parkerson 2011).

As we started to work with students who were referred by course coordinators, I discovered that there were some aspects of academic writing that most undergraduate students found unfamiliar and challenging. These included, for example, difficulties with knowing how to respond appropriately to different components of an essay topic, even if guidelines were provided. Other examples included being unfamiliar with the basic components of an academic essay; activities involved in planning for writing, such as using pre-writing techniques to generate and organise ideas for writing or selecting; analysing and incorporating suitable literature in their writing; the need for referencing sources in academic writing; not having models of writing that could assist them to formulate introductions, academic arguments, and conclusions to their academic writing; and making sense of lecturer feedback (Clarence 2011, Deyi 2011, Leibowitz and Parkerson 2011). At the time, my only strengths in these areas included the fact that I was a capable student writer who could express my ideas in writing fairly well, and I enjoyed applying my technical skills of academic writing to my own studies. I had also received some training in how to assist others to develop their own academic writing abilities.

I also discovered that being a writing consultant was considerably different from being a subject tutor. Our training included a conscientising about facilitative consulting techniques, developing a certain ethos based on principles of Positive Psychology, developmental education, and collaborative/reciprocal peer learning, formative assessment strategies, and discursive strategies that were aimed at strengthening students as writers by means of collaborative and discovery learning. Subject tutors usually adopted a tutoring style that was mostly intended to reinforce and align with current classroom teaching that occurred in lectures. Consulting in a writing centre, on the other hand, was more flexible in approach. Writing consultations were mainly about one-to-one teaching and learning relationships with student writers. The focus of any initial consultation depended on an individual student's assignmentdriven writing needs, which enabled a writing consultant and student writer to start mapping other areas of writer development that kept such relationships going as student-centred endeavours and not curriculum-centred processes. The only times when consulting work was homogenous to some extent was when groups of students enrolled in a particular course were referred to the Centre as part of a structured relationship between the ADC and a university department. Across the board, our team of writing consultants would become aware of what students found to be the most challenging aspects of a particular assignment, and what difficulties students were experiencing as academic writers (Leibowitz and Parkerson 2011). 
Throughout this period, between the mid-1990s until the early 2000s, I would argue that my personal agency was developed considerably. As a writing consultant, I became adept at using my knowledge of what an undergraduate student writer typically found challenging about academic writing, and applying that knowledge during writing consultations or workshops within the cultural space of a writing centre. I regard this phase or cycle as a morphogenetic cycle made up of morphogenetic and morphostatic elements. Reinforcement of ethos and value prescripts of building a writing centre culture in context was the main area of development. My personal agency, and the personal agency of my fellow writing consultants, contributed to ensuring that the writing centre as a different pedagogical space could develop as a cultural space.

During this time, however, I also developed an awareness of cultural and structural constraints in relation to writing centres. We were attempting to build a counter-culture (of a positive kind) that prioritised the teaching and learning needs of a student-focused educational environment within the confines of a small centre that could not accommodate all the students who could benefit from our approach and methods of teaching and learning. The structures that students were mainly exposed to were lecture theatres where large classes and a transmission mode of teaching and learning were the norm. Within institutional committee structures, the ethos or values base of the writing centre was considered alien, rather interesting, perhaps worth trying, but still just an experiment. In the building of this "new" type of teaching and learning space, elements of morphostasis included our resistance to compromise on the type of cultural space we were building, while resigning ourselves to the fact that we were being inhibited by normative ways of teaching in the university (see, for example, Leibowitz and Parkerson 2011; Nichols 2011: 22-25; Daniels, Richards and Lackay 2017: 60; Slemming 2017: 27-28).

\subsection{Story B - The Middle Period}

This narrative is about my development as a manager of a writing centre, and my involvement in organisational work in which writing centres are involved. I spent two years as a workshop coordinator at the University of the Western Cape Writing Centre. It was a new job role, and I had to design the scope of activities for the role and configure the activities for different audiences and purposes. It was an interesting role, one which highlighted the necessity to raise awareness among students and staff about the importance of academic writing development by means of learning new skills and techniques to manage the processes of writing. I discovered that the role opened up a space to work multilaterally with groups of students, and to create intellectual links between courses and the writing centre by means of structured, extended relationships involving students, their course coordinators, and writing centre staff. Each new relationship was an opportunity to raise awareness, and to encourage student writers to develop their abilities as writers. Several long-term consulting relationships with student writers started with a writing workshop which they had attended.

When I became the coordinator of this writing centre, I had access to other institutional forums where I could represent the interests of the centre in partnership with colleagues representing faculty interests, and the interests of university management structures. I discovered that there was not a strong, institutionally coordinated infrastructure in which the centre could function, although the culture within the broader institution was positively reinforcing, and aligned to the values and mission of a historically disadvantaged university. I discovered that the main constraints preventing strengthening of the writing centre as an institutional project was a sustainable funding model that could ensure greater job security 
and better material resources for the centre. The reporting line was also quite tenuous for some time after the ADC became decentralised following a rationalisation process in the late 1990s. In the absence of an institutional structure of which this writing centre could form part, the benefit of having a direct reporting line to a member of university management was curtailed by the absence of a formal, in-between structure who could deliberate about issues affecting the role and function of the writing centre in context and as part of institutional decision-making. This situation improved marginally in the early 2000s, when an Academic Development Forum was established that became a discussion forum where input into matters of institutional importance could be shared and reported on as part of institutional decisionmaking processes. Nearly a decade ago, a Directorate of Teaching and Learning was also established following a lengthy strategic-planning process at the university.

During this period, academic development staff in the country organised to establish a national association. The Higher Education Learning and Teaching Association of Southern Africa (HELTASA) was established in 2005 to represent and advocate for the concerns of academic development practitioners and researchers with regard to student, staff, and curriculum development. HELTASA is concerned with promoting the role of teaching and learning in higher education, in a system where funding is awarded for research output, rather than teaching and learning quality and student throughput rates, because research output is considered more tangible and beneficial to the system (HELTASA 2006: 1). The network of writing centres decided to be a Special Interest Group of HELTASA due to the fact that writing centres have been part of academic development projects since the mid-1990s. I served as a member of the HELTASA Executive Committee during the first years of the Association, and discovered that there was a high level of interest among higher education practitioners to participate in HELTASA events and opportunities. New academic staff, in particular, found the Association to be a supportive space where they could share their professional concerns and develop aspects of their roles as academic practitioner-researchers.

This period was also one of the most challenging times for writing centres in their institutional locations. As some writing centres were trying to secure their place in their institutions' committee structures, and as legitimate, institutionally-funded spaces for teaching and learning in their universities, new centres were being established on university campuses around the country. The morphogenetic cycle during this period, I would argue, was one composed of several loosely connected mini-cycles in which different centres were undergoing different growth trajectories. It was also an expansive cycle as several initiatives got underway that have come to form part of an emerging sustainability model of national networking. Writing centre staff, as a HELTASA Special Interest Group, could benefit from participating at HELTASA events more regularly and actively in the future as it could lead to better representation of the Special Interest Group, and the formation of a more closely connected network of writing centre staff in the professional Association to which it is affiliated, which is equitably supported and represented by older and newer generations of writing centre practitioner-researchers.

\subsection{Story C - Recent Developments}

This mini-narrative is about the past 10 to 15 years, and the functioning of the network of writing centres in the country. South African writing centre practitioners have found ways and 
means to maintain their national network activities, and to encourage links with colleagues based at Southern African higher education institutions.

Although writing centre mini-conferences were held since the first number of centres were established in 1994, more writing centre coordinators, consultants, and administrators started to attend annual Writing Centre Indabas (mini-conferences) since the early 2000s, mainly as an annual meeting forum for a growing number of writing centre practitioners. This space was used to conduct regional meetings, professional development workshops, and to present research. Colleagues at the Stellenbosch University Writing Lab also created a Listserv for writing centrenetwork staff, which continues to be a useful communication channel for sharing information nationally, and maintaining discussions and collaborations in the periods between Indabas.

Discussions at the Indabas centre on aspects of writing centre work, theories and pedagogies informing practice, and how writing centres build relationships with students and staff at their respective institutions. Examples of the latter include special advertising campaigns, collaborations in writing-intensive courses, and during orientation programmes at their institutions. These events enable those working in writing centres to share their professional concerns and successes with one another, and is also a useful forum for learning about contextual differences that impact the work of different writing centres in the country. In the past 15 years, with a steady presence of writing centre managers and practitioners at these Indabas, debates about the sustainability of writing centres in South African higher education institutions, the role of research, and professionalising writing centres as academic centres led to the setting of new goals for how writing centres could strengthen their networking activities. One of the well-received initiatives that has been approved by writing centre staff is to establish a formal association for writing centres that could be a forum for collaboration in South Africa and further afield.

The national network of writing centres/labs make use of a well-established Listserv, a Facebook page, an annual Indaba, annual Special Interest Group meetings at the HELTASA conference, and have collaborated to produce two peer-reviewed books about writing centres as part of their networking activities. As already mentioned, this network is currently also engaged in a process of establishing an association for managers, writing consultants/tutors, and researchers who work in writing centres or conduct research on academic writing in writing centre contexts in southern Africa. Thus, there is an evolving network of professionals who continue to work towards strengthening the contexts in which writing centres function. I consider this initiative to be an example of Archer's reference to what Actors can do, not only as individuals, but as a collective of corporate agents. It is an example of another emerging morphogenetic cycle in which people in writing centres are developing beyond being corporate agents to using the best of personal, cultural, and structural emergent properties to act in the interests of mutual development.

\section{Understanding agency using the morphogenetic approach}

As an example, I reflected on my early experiences as a writing centre consultant who had undergone training to conduct my work in a writing centre environment in the 1990s. I supported the discourses around transformation, quality, and teaching and learning that formed part of the new cultural space in which I was working at the time, and tried to uphold, utilise, and reinforce the pedagogical style and ethos that formed part of the values and philosophical basis of such an environment. As a writing consultant, I remained in a reciprocal teaching and 
learning relationship with the writing centre environment (structure and culture), and was involved in recurring opportunities to replicate the use of suitable consulting techniques with students during writing consultations. A well-trained writing consultant is an asset to a writing centre and, as I gained consulting experience, I found myself better able to reinforce the morphostatic elements of an emerging structure and culture that differentiate writing centres from other types of teaching and learning spaces.

I also developed personal emergent properties over time, as I continued to interact with different consulting and relationship-building scenarios, and administrative issues in a management role in the writing centre. I noticed areas where consulting practice could be improved, and I developed a sense of responsibility to advocate for the writing centre as a teaching and learning space to audiences beyond the structure of the writing centre in which I worked. I developed an awareness that these structures and cultures, at times, constrained or cultivated agency, and that there were reciprocal influences between structure/culture on my sense of agency, and between agency and structure/culture in different morphogenetic cycles. I learned to compare and evaluate by looking for congruence or dissonance between the writing centre as a structured space in an institutional culture configured in particular ways, and between the writing centre in which I worked in relation to other writing centres and in the field of higher education teaching and learning.

The importance of reflexivity comes to the fore in considerations about human agency, especially as it relates to how individuals view themselves in relation to the social structure or culture in which they function. The transitivity of human experience leads to the possibility of the changing nature of objects of knowledge, and it is through reflexive strategies that individuals are able to develop a coherent interpretation of lived experience. As part of this morphogenetic process of a human agent, Archer discusses the "internal conversations" that individuals have by reflecting, deliberating, and distilling knowledge and learning from their experiences and encounters with social structures and cultures.

For example, I discovered that social integration is simpler to work towards as a corporate goal than system integration. Social integration occurs almost imperceptibly over time in interactions among peers who share the same professional values and philosophical approach to practice. Relationships are usually horizontally structured, and interactions are usually organised and focused around a common purpose. These relationships tend to represent the necessary relationships to which Archer refers, which can lead to interplay between structure/culture and agency from which the emergence of something new - such as a new social practice or structural elaboration in terms of an initiative that is aimed at developing the cultural domain in which interactions between agents occur - comes into being as a result of the interactions between the "parts" and the "people". However, such horizontally-structured relationships can become characterised as peer networks in which only a small number of "corporate agents" participate actively and continuously on a long-term academic development project that encourages professional staff development and the establishment of a professional association for writing centre practitioner-researchers.

System integration is more challenging as the relationships are contingent upon a set of hierarchically informed and structured relationships and interactions that are framed within a larger constellation of processes involving academic units or departments, higher education institutions, professional associations, national regulatory bodies, and the Department of Higher Education and Training. Inevitably, in the absence of transparent leadership goals, clearly 
articulated roles and structured avenues for different role-players, and agential "voices" to be heard, system integration can easily become relegated to the realm of contingent relationships at lower levels of such hierarchically-structured relationships.

However, "corporate agents" at higher education institutions and in HELTASA, for example, could advocate for the following in order to develop the work of writing centres. As a HELTASA Special Interest Group, South African writing centres became affiliated to a professional organisation with the objectives of promoting recognition of teaching and research, and supporting the professional development of academic development staff. HELTASA also encourages the development of professional associations and networks for academic development staff (HELTASA 2006: 1). The role and development objectives of this Special Interest Group could be enhanced if more writing centre practitioners could also regularly attend and participate in HELTASA projects and events, especially since a structured link exists at HELTASA to be supported with the establishment of an organisation for writing centres. Similar links are necessary in higher education institutions where writing centres exist. As members of committee structures, the roles, responsibilities and activities of writing centres could be discussed and included as part of institutional decision-making. As another morphogenetic cycle, linking in such structured ways could perhaps shift contingent relationships to the status of necessary relationships for South African writing centres and the institutional and organisational spaces to which writing centres are affiliated.

\section{Conclusion}

This article attempted to reflect on the affordances of Social Realism as a theoretical framework for considering and making sense of my professional development in a writing centre context. Key concepts relating to Critical Realism - the under-labouring theory to Social Realism - were briefly discussed to provide insight into how functioning within the world is viewed from Critical and Social Realist perspectives. My understanding of concepts that form the basic premise of the Social Realist theoretical framework were then explained, and examples were provided to describe how I understand the concepts of 'analytical dualism', 'conflationary thinking', 'emergence', 'social and system integration', and what constitutes 'morphostasis' and 'morphogenesis'. Thereafter, human 'agency', as a sensemaking concept that writing centre practitioners and researchers can use to deliberate about their own development, was also discussed as the focus concept used in this article. I have attempted to relate these concepts to how my interactions with the social culture and structure dimensions of working in a writing centre context could have played a role in my professional development and the emergence of morphogenesis, or reinforcement during morphostasis, on personal, cultural, and structural levels over a period of 25 years.

The mini-narratives presented suggest that morphogenesis has occurred every decade (not necessarily as distinct time periods) since the first writing centres were established, and that the focus has been shifting towards seeking a better balance between developing practitioner roles and researcher roles inhabited by those who work in writing centres in South Africa. There also appears to be movement towards advancing a research agenda, and using communication forums more effectively as modes of collaborative community or cultural building. I would argue that the network of writing centres in South Africa is involved in a cycle of growth and development as a national and southern African intellectual network, and that the impetus behind initiatives should be - and can be - sustained by those involved in this area of work. I 
would argue that responsiveness that is based on a visualisation of the vertical and horizontal alignment and expansion of the network of writing centres in South Africa is the current imperative. Hopefully, more holistic development of this network is an aspect of writing centre scholarship and professional development where experienced managers, practitioners, and researchers in writing centres could take the lead to pave the way for the next generation of writing centre professionals.

\section{References}

Anderson, L. 2006. Analytical autoethnography. Journal of Contemporary Ethnography 35(4): $373-395$.

Archer, M.S. 1995. Realist social theory: The morphogenetic approach. Cambridge: Cambridge University Press.

Archer, M.S. 1996. Culture and agency: The place of culture in social theory. Cambridge: Cambridge University Press.

Archer, M.S. 2000. Being human: The problem of agency. Cambridge: Cambridge University Press.

Archer, M.S. 2007. Making our way through the world: Human reflexivity and social mobility. Cambridge: Cambridge University Press. https://doi.org/10.1017/cbo9780511618932

Archer, M.S. 2010. Conversations about reflexivity: Ontological explorations. London: Routledge.

Bhaskar, R. 1998. The possibility of naturalism: A philosophical critique of the contemporary human sciences. London: Routledge.

Bhaskar, R. 2008. A realist theory of science. London: Routledge.

Bhaskar, R. 2009. Scientific realism and human emancipation. London: Routledge.

Bochner, A. and C. Ellis. 2006. Communication as autoethnography. In G.J. Sheppard, J.S. John and T. Striphas (eds.) Communication as autoethnography: Perspectives on theory. Thousand Oaks, CA: Sage. pp. 110-122. https://doi.org/10.4135/9781483329055.n13

Brodkey, L. 1996. I-site. Literacy and Numeracy Studies 6(2): 17-30.

Buckley, W. 1967. Sociology and modern systems theory. New Jersey: Prentice Hall.

Carter, B. and C. New. 2004. Making realism work: A realist social theory and empirical research. London: Routledge.

Chang, H-W. 2008. Autoethnography as method. Walnut Creek, CA: West Coast Press.

Clarence, S. 2011. Writing in the academy: Collaborative writing development with students and lecturers at the UWC Writing Centre. In A. Archer and R. Richards (eds.) Changing spaces: Writing centres and access to higher education. Stellenbosch: SUN MeDIA. pp. 101-114. 
Danermark, B., M. Ekström, L. Jakobsen and J.C. Karlsson. 2002. Explaining society: Critical realism in the social sciences. London: Routledge.

Daniels, S., R. Richards and A. Lackay. 2017. The Writing Lab in the centre: A collaborative model for integrating writing consultations in a first-year Engineering module. In S. Clarence and L. Dison (eds.) Writing centres in higher education: Working in and across the disciplines. Stellenbosch: SUN MeDIA. pp. 129-143. https://doi.org/10.18820/9781928357551

Denshire, S. 2013. Autoethnography. Sociopedia.isa: 1-12. Available online: http://www.sagepub.net/isa/resources/pdf/Autoethnography.pdf (Accessed 19 July 2019). https://doi.org/10.1177/205684601351

Deyi, S. 2011. Feedback or feed-forward? Implications of the language used in giving feedback on students' writing. In A. Archer and R. Richards (eds.) Changing spaces: Writing centres and access to higher education. Stellenbosch: SUN MeDIA. pp. 47-58.

Ellis, C. and A. Bochner. 2000. Autoethnography, personal narrative, reflexivity: Researcher as subject. In N.K. Denzin and Y.S. Lincoln (eds.) Handbook of qualitative research. London: Sage. pp. 733-768.

Ellis, C., T. Adams and A. Bochner. 2011. Autoethnography: An overview. Historical Social Research 36(4): 273-290.

HELTASA. 2006. The Constitution of the Higher Education Learning and Teaching Association of Southern Africa (HELTASA). Available online: heltasa.org.za/wpcontent/uploads/2018/05/The-Constitution-of-HELTASA.pdf (Accessed 7 June 2018).

Leibowitz, B. and A. Parkerson. 2011. A conversation about the UWC Writing Centre Project. In A. Archer and R. Richards (eds.) Changing spaces: Writing centres and access to higher education. Stellenbosch: SUN MeDIA. pp. 75-89.

Méndez, M. 2013. Autoethnography as a research method: Advantages, limitations and criticisms. Colombian Applied Linguistics Journal 15(2): 279-287. https://doi.org/10.14483/ udistrital.jour.calj.2013.2.a09

Miller, R. and J. Brewer. (eds.) 2003. The A-Z of social research: A dictionary of key social science research concepts. London: Sage.

Mizzi, R. 2010. Unraveling researcher subjectivity through multivocality in autoethnography. Journal of Research Practice 6(1): 1-13. Article M3. Available online: http://jrp.icaap.org/index.php/jrp/article/view/201/185 (Accessed 24 June 2019).

Motshoane, P. and S. McKenna. 2014. More than agency: The multiple mechanisms affecting postgraduate education. In M. Fourie-Malherbe, R. Albertyn, C. Aitchison and E. Bitzer (eds.) Pushing boundaries in postgraduate supervision. Stellenbosch: SUN MeDIA. pp. 185-202. https://doi.org/10.18820/9781928357223 
Nichols, P. 2011. Student culture and cultural change: A manifesto for writing praxis in a South African writing centre. In A. Archer and R. Richards (eds.) Changing spaces: Writing centres and access to higher education. Stellenbosch: SUN MeDIA. pp. 19-27.

Quinn, L. (ed.) 2012. Re-imagining academic staff development: Spaces for disruption. Stellenbosch: SUN MeDIA. https://doi.org/10.18820/9781920338879

Sayer, A. 2000. Realism and social science. London: Sage.

Sibeon, R. 2004. Rethinking social theory. London: Sage.

Slemming, F. 2017. The place of education theories in writing centres: Why this makes for significant research. In S. Clarence and L. Dison (eds.) Writing centres in higher education: Working in and across the disciplines. Stellenbosch: SUN MeDIA. pp. 19-33. https://doi.org/10.18820/9781928357551

Vorster, J. 2010. A Social Realist Analysis of Collaborative Curriculum Development Processes in an Academic Department at a South African University. Unpublished PhD dissertation, Rhodes University.

Willmott, R. 2002. Education policy and realist social theory. Primary teachers, child-centred philosophy and the new managerialism. London: Routledge. https://doi.org/10.4324/978 $\underline{0203166536}$ 